\title{
AGE- AND GENDER-SPECIFIC PREVALENCE OF SELF-REPORTED SYMPTOMS IN ADULTS
}

\author{
Zalika Klemenc-Ketiš ${ }^{1,2}$, Miljenko Križmarić1, Janko Kersnik ${ }^{1,2}$ \\ 'Department of Family Medicine, Medical School, University of Maribor, Maribor, Slovenia \\ ${ }^{2}$ Department of Family Medicine, Medical School, University of Ljubljana, Ljubljana, Slovenia
}

\section{SUMMARY}

Objective: The aim of the study was to determine the age- and gender-specific prevalence of predefined symptoms in adults.

Methods: Cross-sectional study using a method of computer assisted telephone interview.

Results: At least one of the symptoms was experienced by $71.4 \%$ of men and $84.6 \%$ of women in the past month. Most common symptoms in men were back pain, joint pain, irritability, nervousness, and muscle pain; in women back pain, joint pain, fatigue, headache, and nervousness. The trend of symptoms' prevalence through the age groups was increasing, stable or biphasic.

Conclusions: The results from this study are important for recognizing and understanding of symptoms' self-perception in both genders.

Key words: signs and symptoms, gender, adult population, cross-sectional study

Address for correspondence: Z. Klemenc-Ketiš, Kersnikova 1, 3320 Velenje, Slovenia. E-mail: zalika.klemenc-ketis@uni-mb.si

\section{INTRODUCTION}

Prevalence of morbidity and co-morbidity is increasing with age $(1,2)$. Therefore, one could anticipate that higher age would be associated with higher prevalence of symptoms as these are supposed to mirror the presence and development of the underlying diseases. But several studies have indicated otherwise (3-6). Taken into account many common symptoms, the results of these studies have shown that the prevalence of some symptoms increases with age (i.e. sleeping disturbances, hearing problems, joint and leg pain), while the prevalence of other symptoms decreases (i.e. general fatigue, headache, nausea), remains stable during life span (i.e. coughing, breathlessness, diarrhea, chest pain, constipation, nervousness, poor appetite) or has a biphasic prevalence pattern (i.e. sweating and impaired concentration) (3, $4,7)$. Reasons for such results are probably multifaceted, ranging from the effect of physiological effects of anxiety or other factors (4) to the effect of socioeconomic and lifestyle factors (8-11). There is also a gender-related common belief that women complain of health problems more often than men and present more symptoms than men of the same age.

There are just a few studies addressing the prevalence of symptoms in general population $(5,6,12)$. Other studies on this topic have mainly addressed specific population, such as middleaged women $(3,13-16)$, adolescents and younger people (17, 18) and older patients (19). Other studies have reported overall prevalence of individual symptoms $(5,6,20-22)$. One older study (4) focused on symptoms by age and gender in a general population of one city in Sweden. Its results indicated that there were no differences in age-related pattern of symptoms according to gender but women in general presented more symptoms than men. It also detected three types of symptoms prevalence pattern: increasing, decreasing and curvilinear shape with a peak at the age of 50 (4). Other important publications on the topic mainly use surrogate measures of symptoms' presentation in the population of the pooled data from primary studies on seeking medical help and use of health care services (23). On the other hand, data on service utilization and registered diagnoses are derived mainly from secondary care sources and from the disease management in health care environment and are less helpful in addressing illness presentation in the population (24).

In the past years, the society experienced many changes (25) which inevitably influenced health status and people's health perceptions (26). Increasing age and longer life expectancy resulted in higher prevalence of morbidity and changed the management of such patients which might have influenced also the symptoms' prevalence. As no studies on symptoms' prevalence in representative samples of general population have been known to the authors, we decided to perform this study. Its main aim was to determine the age and gender specific prevalence of predefined symptoms in the adult Slovenian population.

\section{MATERIALS AND METHODS}

\section{Study Design}

The data reported in this article were collected in a large observational cross-sectional study conducted in the general population of Slovenia in June 2011. They were collected by a method of computer assisted telephone interview (CATI) (27). CATI is a suitable and efficient method for data collection in social sciences. It enables researches to reach a high number of subjects, to minimize errors of recording, and to simplify the handling of collected data.

The CATI procedure is standardized. Trained interviewers use automatic dialing to contact persons in a sample. If a person does not answer, he or she is contacted repeatedly. In case that a 
person does not wish to participate, another person with similar demographic characteristics is found (27). The Slovenian National Ethics Committee approved the study (No. 105/04/09).

\section{Participants}

We included a representative sample of 1,002 randomly selected Slovenian citizens stratified according to gender and age to reflect the demographic characteristics of Slovenian population (28). People younger than 15 years of age were excluded from the sampling. Prior to the interview, the respondents gave their oral informed consent.

The sampling was based on the Slovenian telephone book.

\section{Data Collection}

We collected data with a questionnaire based on the Subjective Health Complaints Inventory (SHC) (29) and on the Complaint Score - a subscale of the Gothenburg Quality of Life Instrument (30). Here, we only report on the questions that were used for this article. These were demographic questions (Table 1) and questions about the prevalence of symptoms (Table 2). The demographic questions were of a closed type; the respondents had to choose one option from the available options. In the part about the symptoms, the respondents had to answer closed type questions on whether or not they had experienced individual symptoms for at least one day in the month prior to the telephone interview. The list of symptoms (Table 2) was also developed by the authors so the respondents did not have the opportunity to report freely on their symptoms.

Table 1. Demographic characteristics of the sample according to gender

\begin{tabular}{|l|c|c|c|}
\hline Characteristic & $\begin{array}{c}\text { Number (\%) } \\
(\mathrm{N}=1,002)\end{array}$ & $\begin{array}{c}\text { Number } \\
(\%) \text { of men } \\
(\mathrm{N}=490)\end{array}$ & $\begin{array}{c}\text { Number (\%) } \\
\text { of women } \\
(\mathrm{N}=512)\end{array}$ \\
\hline Education & $129(12.9)$ & $52(10.6)$ & $77(15.1)$ \\
\hline Primary & $186(18.6)$ & $101(20.6)$ & $85(16.6)$ \\
\hline Vocational & $391(39.0)$ & $199(40.5)$ & $192(37.6)$ \\
\hline Secondary & $275(27.4)$ & $128(26.1)$ & $147(28.8)$ \\
\hline University & $21(2.1)$ & $11(2.2)$ & $10(1.0)$ \\
\hline Postgraduate & $472(47.1)$ & $308(62.9)$ & $265(51.8)$ \\
\hline Employment status & $96(9.6)$ & $36(7.4)$ & $61(11.9)$ \\
\hline Employed/student & $312(31.1)$ & $132(27.0)$ & $180(35.2)$ \\
\hline Unemployed & $265(26.5)$ & $107(22.7)$ & $158(21.7)$ \\
\hline Retired & $191(19.0)$ & $83(17.6)$ & $108(21.7)$ \\
\hline Income (reference to 950 EUR per month) \\
\hline Much less & $182(18.1)$ & $103(21.8)$ & $79(15.9)$ \\
\hline Partly less & $149(14.8)$ & $74(15.7)$ & $75(15.1)$ \\
\hline Almost the same & $42(4.2)$ & $34(7.2)$ & $8(1.6)$ \\
\hline Partly more & $141(14.1)$ & $71(15.0)$ & $70(14.1)$ \\
\hline Much more & & \\
\hline No income & & \\
\hline
\end{tabular}

Table 2. The prevalence of symptoms in the past month according to gender

\begin{tabular}{|l|c|c|c|}
\hline Symptom & $\begin{array}{c}\text { Number (\%) } \\
\text { of men }\end{array}$ & $\begin{array}{c}\text { Number (\%) } \\
\text { of women }\end{array}$ & $\mathbf{p}$ \\
\hline Back pain & $182(37.1)$ & $226(44.1)$ & 0.025 \\
\hline Joint pain & $136(27.8)$ & $198(38.7)$ & $<0.001$ \\
\hline Irritability & $122(24.8)$ & $140(27.3)$ & 0.389 \\
\hline Nervousness & $116(23.7)$ & $169(32.9)$ & 0.001 \\
\hline Muscle pain & $113(23.1)$ & $143(27.9)$ & 0.082 \\
\hline Fatigue & $112(23.1)$ & $196(38.2)$ & $<0.001$ \\
\hline Excessive sweating & $111(22.7)$ & $110(21.5)$ & 0.703 \\
\hline Insomnia & $98(20.0)$ & $161(31.4)$ & $<0.001$ \\
\hline Eye problems & $95(19.4)$ & $122(23.8)$ & 0.092 \\
\hline Headache & $93(19.0)$ & $187(36.5)$ & $<0.001$ \\
\hline Memory impairment & $90(18.4)$ & $127(24.9)$ & 0.014 \\
\hline Tingling of the extremities & $82(16.7)$ & $125(24.4)$ & 0.003 \\
\hline Restless legs & $80(16.4)$ & $92(18.0)$ & 0.557 \\
\hline Tinnitus & $76(15.5)$ & $69(13.5)$ & 0.370 \\
\hline Hearing problems & $56(11.4)$ & $50(9.8)$ & 0.412 \\
\hline Difficulties in breathing & $40(8.2)$ & $62(12.1)$ & 0.047 \\
\hline Nausea & $40(8.2)$ & $51(10.0)$ & 0.379 \\
\hline Diarrhea & $36(7.3)$ & $33(6.4)$ & 0.619 \\
\hline Chest pain & $35(7.2)$ & $56(10.9)$ & 0.047 \\
\hline Dizziness & $32(6.5)$ & $81(15.8)$ & $<0.001$ \\
\hline Constipation & $28(5.7)$ & $65(12.7)$ & $<0.001$ \\
\hline Poor appetite & $25(5.1)$ & $38(7.4)$ & 0.152 \\
\hline
\end{tabular}

\section{Statistical Analysis}

We used IBM SPSS Statistics 20.0 (Chicago, IL, USA) to analyze the data. For the statistical analysis of the age associations, we created the following age categories: $20-34,35-49,50-64$, and $65-80$. We performed a descriptive analysis and a bivariate analysis (independent t-test and chi-square test). We set the limit for statistical significance at $\mathrm{p}<0.05$. When analyzing the overall prevalence of symptoms in the past month, we created a variable "one month prevalence of symptoms" with values "symptoms present" and "symptoms not present". Respondents who reported at least one symptom present for at least one day in the past month were allocated to the category "symptoms present" and all others were allocated to the category "symptoms not present". When analyzing patterns of symptoms through age categories, individual symptoms were allocated to different groups based on statistical significance and a trend in prevalence.

\section{RESULTS}

Out of 1,002 people in the sample, 490 (48.9\%) were men. Most of the respondents $(391 ; 39.0 \%)$ had secondary school, were employed or studying $(472 ; 47.1 \%)$ and had monthly income much less than 950 EUR $(265 ; 26.5 \%)$ (Table 1). 
At least one symptom in the past month was experienced by $344(71.4 \%)$ men and by $430(84.6 \%)$ women $(p<0.001)$; the one-month prevalence of any symptom in the whole sample was $77.3 \%$. Women experienced significantly more symptoms in one month when compared to men $(4.9 \pm 3.9$ vs. $3.6 \pm 3.8, \mathrm{t}=5.119$, $\mathrm{p}<0.001$ ). Most common symptoms in the whole sample were back pain, joint pain and fatigue, but they were not equally distributed according to gender. For example, fatigue and headache were the most common in women and irritability and muscle pain were the most common in men (Figures 1 and 2). Back pain, joint pain, nervousness, fatigue, insomnia, headache, memory impairment, tingling of the extremities, difficulties in breathing, chest pain, dizziness, and constipation were significantly more common in women than in men (Table 2).

Men who stated that they had experienced symptoms in the past month were significantly older when compared to the men without any symptoms in the past month $(47.4 \pm 17.7$ years vs. $38.8 \pm 15.5$ years, $\mathrm{t}=5.289, \mathrm{p}<0.001)$. Similarly, women who stated that they had experienced symptoms in the past month were significantly older when compared to the women without any symptoms in the past month $(49.2 \pm 19.0$ years vs. $41.1 \pm 15.5$ years, $\mathrm{t}=4.067$, $\mathrm{p}<0.001)$. But when the distribution of symptoms' prevalence was observed through the age groups, several patterns could be

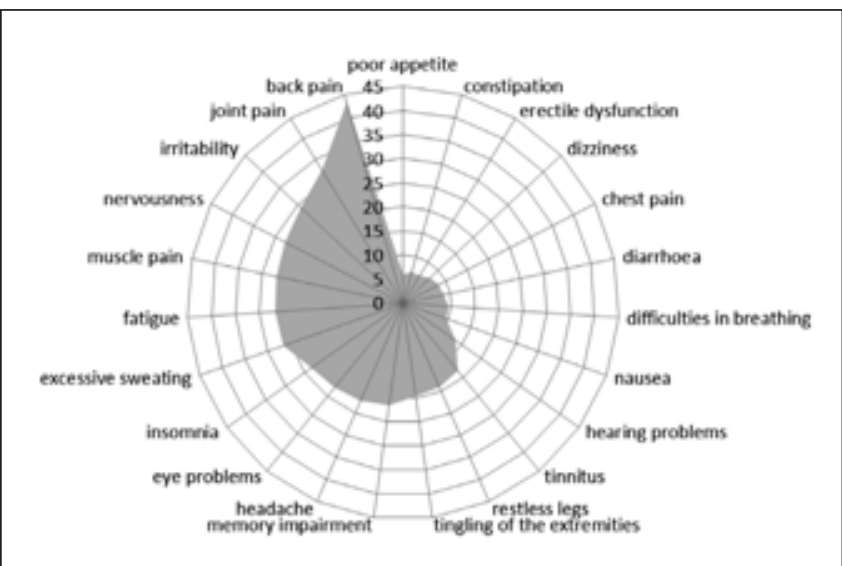

Fig.1. The prevalence of symptoms experienced by men in the past month.

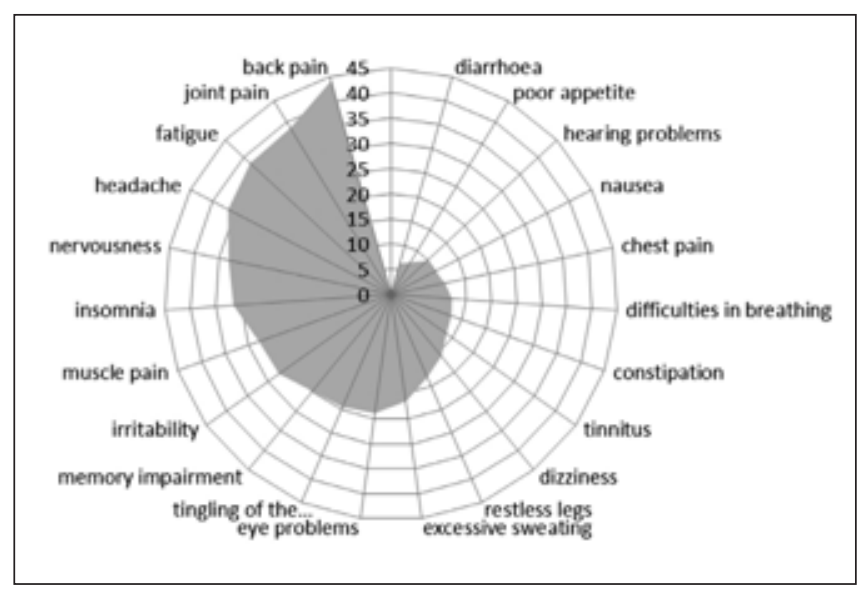

Fig. 2. The prevalence of symptoms experienced by women in the past month.
Table 3. The prevalence of symptoms (\%) in men $(\mathrm{N}=453)$ in the past month according to age

\begin{tabular}{|c|c|c|c|c|c|}
\hline \multirow{3}{*}{ Symptom } & \multicolumn{4}{|c|}{ Age groups (years) } & \multirow{3}{*}{$p$} \\
\hline & \multirow{2}{*}{\begin{tabular}{|l|}
$20-34$ \\
$N=112$
\end{tabular}} & \multirow{2}{*}{$\begin{array}{l}35-49 \\
N=136\end{array}$} & \multirow{2}{*}{$\begin{array}{l}50-64 \\
N=128\end{array}$} & \multirow{2}{*}{$\begin{array}{l}65-80 \\
N=77\end{array}$} & \\
\hline & & & & & \\
\hline \multicolumn{6}{|c|}{ Increasing prevalence (\%) } \\
\hline Back pain & 26 & 35 & 42 & 62 & 0.001 \\
\hline Joint pain & 20 & 23 & 27 & 53 & $<0.001$ \\
\hline Eye problems & 17 & 15 & 27 & 30 & 0.017 \\
\hline Insomnia & 13 & 17 & 23 & 40 & $<0.001$ \\
\hline Memory impairment & 12 & 18 & 19 & 42 & $<0.001$ \\
\hline $\begin{array}{l}\text { Tingling } \\
\text { of the extremities }\end{array}$ & 4 & 14 & 21 & 31 & $<0.001$ \\
\hline Tinnitus & 0 & 16 & 23 & 29 & $<0.001$ \\
\hline Hearing problems & 4 & 9 & 11 & 34 & $<0.001$ \\
\hline Difficulties in breathing & 4 & 7 & 8 & 21 & $<0.001$ \\
\hline Chest pain & 4 & 4 & 6 & 21 & $<0.001$ \\
\hline Dizziness & 0 & 4 & 9 & 19 & 0.016 \\
\hline Erectile dysfunction & 0 & 2 & 7 & 21 & $<0.001$ \\
\hline \multicolumn{6}{|l|}{ Stable prevalence $(\%)$} \\
\hline Nervousness & 29 & 22 & 23 & 22 & 0.521 \\
\hline Fatigue & 25 & 22 & 16 & 36 & 0.349 \\
\hline Irritability & 23 & 26 & 21 & 36 & 0.561 \\
\hline Diarrhea & 11 & 14 & 2 & 4 & 0.396 \\
\hline Nausea & 4 & 7 & 7 & 13 & 0.504 \\
\hline Poor appetite & 3 & 7 & 5 & 5 & 0.425 \\
\hline \multicolumn{6}{|l|}{ Biphasic pattern (\%) } \\
\hline Excessive sweating & 17 & 29 & 21 & 26 & 0.005 \\
\hline Muscle pain & 16 & 26 & 22 & 39 & 0.004 \\
\hline Headache & 15 & 26 & 10 & 23 & 0.011 \\
\hline Restless legs & 13 & 18 & 12 & 27 & 0.017 \\
\hline Constipation & 6 & 4 & 2 & 16 & 0.001 \\
\hline
\end{tabular}

detected (Tables 3 and 4). These were of increasing, stable or biphasic prevalence. In general, symptoms expressed similar prevalence patterns through the age groups when compared to gender. However, some symptoms expressed different gender-agerelated pattern. For example, there was an increasing prevalence in insomnia in men while in women the trend was rather biphasic one. Nervousness showed an increasing prevalence in women and a stable one in men. Also, restless legs showed an increasing prevalence in women and a stable one in men. Muscle pain and restless leg in women increased through the age groups while in men they expressed a biphasic pattern. Constipation had a stable prevalence in women and a biphasic one in men (Tables 3 and 4).

\section{DISCUSSION}

This study showed that in one month time women experienced symptoms more commonly and that they also experienced more 
Table 4. The prevalence of symptoms (\%) in women $(N=484)$ in the past month according to age

\begin{tabular}{|c|c|c|c|c|c|}
\hline \multirow{3}{*}{ Symptom } & \multicolumn{4}{|c|}{ Age groups (years) } & \multirow{3}{*}{$p$} \\
\hline & \multirow{2}{*}{\begin{tabular}{|c|}
$20-34$ \\
$N=124$ \\
\end{tabular}} & \multirow{2}{*}{$\begin{array}{l}35-49 \\
N=120\end{array}$} & \multirow{2}{*}{$\begin{array}{c}50-4 \\
N=122\end{array}$} & \multirow{2}{*}{$\begin{array}{l}65-80 \\
N=118\end{array}$} & \\
\hline & & & & & \\
\hline \multicolumn{6}{|c|}{ Increasing prevalence (\%) } \\
\hline Back pain & 32 & 43 & 52 & 55 & 0.001 \\
\hline Joint pain & 12 & 33 & 52 & 62 & $<0.001$ \\
\hline Nervousness & 25 & 26 & 37 & 38 & 0.034 \\
\hline Muscle pain & 22 & 20 & 30 & 40 & 0.002 \\
\hline Memory impairment & 15 & 15 & 30 & 45 & $<0.001$ \\
\hline $\begin{array}{l}\text { Tingling } \\
\text { of the extremities }\end{array}$ & 11 & 20 & 37 & 32 & $<0.001$ \\
\hline Eye problems & 18 & 17 & 28 & 40 & $<0.001$ \\
\hline Restless legs & 7 & 12 & 23 & 33 & $<0.001$ \\
\hline Dizziness & 12 & 11 & 16 & 25 & 0.016 \\
\hline Tinnitus & 2 & 5 & 20 & 28 & $<0.001$ \\
\hline Difficulties in breathing & 8 & 6 & 16 & 21 & 0.001 \\
\hline Chest pain & 4 & 10 & 13 & 18 & 0.006 \\
\hline Hearing problems & 0 & 8 & 12 & 21 & $<0.001$ \\
\hline \multicolumn{6}{|l|}{ Stable prevalence (\%) } \\
\hline Fatigue & 42 & 34 & 34 & 42 & 0.349 \\
\hline Irritability & 23 & 28 & 30 & 26 & 0.561 \\
\hline Constipation & 10 & 13 & 12 & 15 & 0.720 \\
\hline Poor appetite & 10 & 3 & 4 & 6 & 0.144 \\
\hline Nausea & 7 & 8 & 9 & 13 & 0.504 \\
\hline Diarrhea & 6 & 6 & 4 & 9 & 0.396 \\
\hline \multicolumn{6}{|l|}{ Biphasic pattern (\%) } \\
\hline Headache & 36 & 44 & 34 & 24 & 0.011 \\
\hline Insomnia & 21 & 16 & 41 & 45 & $<0.001$ \\
\hline Excessive sweating & 15 & 16 & 31 & 25 & 0.005 \\
\hline
\end{tabular}

symptoms than men. Even though overall symptoms' prevalence was higher in older age (in both genders), some symptoms expressed stable or biphasic pattern through different age groups.

The one-month prevalence of symptoms found in this study is in line with the work of Green et al. (23) who estimated that in a general population there were 800 people experiencing symptoms in one month. Also, the one-month prevalence of symptoms found in this study was similar as in other studies $(6,12)$. The recent study on a representative sample of Slovenian citizens reported $70.5 \%$ prevalence of chronic diseases (1), which was a little lower than the prevalence of symptoms in this study but this was expected since also people without chronic diseases experience symptoms of acute diseases.

Higher symptoms' prevalence in women is in line with other studies $(4,6,12,18,31,32)$ confirming the assumption that women are more attentive to their well-being and they sooner perceive any ill symptoms or illness (3).

Most common symptoms in both genders were from the field of musculoskeletal disorders which was expected as these diseases are highly prevalent among the general population (1) and confirmed also by other studies $(5,6,12)$. Also, not surprisingly, these symptoms increased with age in both genders. Very high on the list in both genders are less expectedly psychological problems, which are according to reported diagnoses not so often diagnosed in primary care settings $(33,34)$.

The finding of this study that symptoms did not expressed only an age-increasing prevalence but also other patterns is in line with other studies $(3,4,7)$ and indicates that the prevalence of individual symptoms is not necessary associated with higher prevalence of diseases but also with other factors $(4,8-11)$. In this study, there were some gender differences in the age-related prevalence pattern of some symptoms such as insomnia, nervousness and restless legs. Since these symptoms are mainly associated with psychological and sociological problems, this further confirms the above statement that many other factors but somatic ones could contribute to the individual's perception of symptom or illness (26). This could also be reflected in the finding of this study that the symptoms found to be significantly more common in women were mainly from the psychological field.

In this study, we did not detect any decrease in symptoms' prevalence neither in men nor in women. On the other hand, the results of other studies suggest that some symptoms such as general fatigue, headache, irritability, melancholy, backache, exhaustion, feeling cold, crying easily, abdominal pain, dizziness, and nausea might decrease with age in women (3) and some symptoms such as abdominal pain, nausea, diarrhea, cough, and headache might decrease with age in the general population (4, 12). The possible reason is a methodological one. Namely, there are considerable differences between this study and other studies in a sample size, age groups and questionnaires. In this study, we took a large age-interval (from 20 to 80 years of age), which might reflect the failure in detecting the decreasing symptoms' pattern.

Surprisingly, we found a large number of different vague symptoms in both women's and men's group, underpinning the importance of primary care offering gate-keeping system. Many of these symptoms can originate from different medical areas and patients would not be able to self-refer themselves to the appropriate clinical specialist without a consultation with a primary care specialist. Diversity of all symptoms experienced in one month in the general population is also difficult to manage without adequate training in primary care management (35), which can offer holistic approach in the comprehensive management of acute and chronic health problems as well as physical, psychological, emotional, and existential origin of the patient problems (36).

The main advantages of our study are a large representative sample of the general population (28) as the basic demographic characteristics of the sample did not differ substantially from the population itself. Another advantage is the use of a proven methodology $(16,27)$. The biggest limitation of this study is its cross-sectional design, which does not allow us to detect the actual age differences. Also, the age groups had large intervals, therefore, the study was prone to inaccurate detection of age-related symptoms' prevalence. Since participants self-reported their symptoms, this could have added to a bias. The main limitation of the CATI methodology is a selection bias because the interview is based on the telephone book and does not include the individuals not listed in it. Also, there is a problem of non-respondents which were not recorded, therefore, the actual response rate is not known. This 
could also lead to the selection bias although the CATI methodology actively seeks the demographically appropriate respondents instead of non-respondents thus minimizing the selection bias. A common problem with the CATI technique is the underreporting of data which might decrease the prevalence of symptoms. Therefore, one must be careful when generalizing the data to the whole population or to the other populations.

This study points to the age and gender differences in symptoms' prevalence of the general population. Although some symptoms included in this study are of a wide spectrum and thus no conclusions in specific health problems can be drawn, the findings are still important as they reflect the actual health problems experienced by the general population which are often not specific and vague. The results of this study are important not only for recognizing and understanding of the general population self-perception of health symptoms in both genders but also in guiding education of students and family doctors in a way that they acknowledge a variety of symptoms present in the general population and know how to address the presentation of these symptoms when people seek medical care.

\section{Conflict of Interest}

None declared

\section{REFERENCES}

1. Softič N, Smogavec M, Klemenc-Ketiš Z, Kersnik J. Prevalence of chronic diseases among adult Slovene population. Zdrav Var. 2011;50:185-90. (In Slovenian.)

2. Dalstra JA, Kunst AE, Borrell C, Breeze E, Cambois E, Costa G, et al. Socioeconomic differences in the prevalence of common chronic diseases: an overview of eight European countries. Int J Epidemiol. 2005 Apr;34(2):316-26.

3. Bardel A, Wallander MA, Wedel H, Svärdsudd K. Age-specific symptom prevalence in women 35-64 years old: a population-based study. BMC Public Health. 2009 Jan 26;9:37.

4. Tibblin G, Bengtsson C, Furunes B, Lapidus L. Symptoms by age and sex. The population studies of men and women in Gothenburg, Sweden. Scand J Prim Health Care. 1990 Mar;8(1):9-17.

5. Ihlebaek C, Brage $\mathrm{S}$, Eriksen HR. Health complaints and sickness absence in Norway, 1996-2003. Occup Med (Lond). 2007 Jan;57(1):43-9.

6. Eriksen HR, Svendsrod R, Ursin G, Ursin H. Prevalence of subjective health complaints in the Nordic European countries in 1993. Eur J Public Health. 1998;8(4):294-8.

7. Dionne CE, Dunn KM, Croft PR. Does back pain prevalence really decrease with increasing age? A systematic review. Age Ageing. 2006 May;35(3):229-34.

8. Furunes B, Bengtsson C, Lapidus L. Subjectively experienced symptoms in relation to socio-economic factors in women. Eur J Epidemiol. 1996 Dec;12(6):617-24.

9. Stadberg E, Mattsson LA, Milsom I. The prevalence and severity of climacteric symptoms and the use of different treatment regimens in a Swedish population. Acta Obstet Gynecol Scand. 1997 May;76(5):442-8.

10. Ivarsson T, Spetz AC, Hammar M. Physical exercise and vasomotor symptoms in postmenopausal women. Maturitas. 1998 Jun 3;29(2):13946.

11. Hunter MS. Predictors of menopausal symptoms: psychosocial aspects. Baillieres Clin Endocrinol Metab. 1993 Jan;7(1):33-45.

12. Ihlebaek C, Eriksen HR, Ursin H. Prevalence of subjective health complaints (SHC) in Norway. Scand J Public Health. 2002;30(1):20-9.

13. Berecki-Gisolf J, Begum N, Dobson AJ. Symptoms reported by women in midlife: menopausal transition or aging? Menopause. 2009 SepOct;16(5):1021-9.

14. Dennerstein L, Lehert P, Koochaki PE, Graziottin A, Leiblum S, Alexander JL. A symptomatic approach to understanding women's health experiences: a cross-cultural comparison of women aged 20 to 70 years. Menopause. 2007 Jul-Aug;14(4):688-96.
15. Melby MK. Climacteric symptoms among Japanese women and men: comparison of four symptom checklists. Climacteric. 2006 Aug;9(4):298304.

16. Ketola E, Klockars M. Computer-assisted telephone interview (CATI) in primary care. Fam Pract. 1999 Apr;16(2):179-83.

17. Réthelyi JM, Berghammer R, Ittzés A, Szumska I, Purebl G, Csoboth C. Comorbidity of pain problems and depressive symptoms in young women: results from a cross-sectional survey among women aged 15-24 in Hungary. Eur J Pain. 2004 Feb;8(1):63-9.

18. Leikanger E, Ingul JM, Larsson B. Sex and age-related anxiety in a community sample of Norwegian adolescents. Scand J Psychol. 2012 Apr;53(2):150-7.

19. Wolitzky-Taylor KB, Castriotta N, Lenze EJ, Stanley MA, Craske MG. Anxiety disorders in older adults: a comprehensive review. Depress Anxiety. 2010 Feb;27(2):190-211.

20. Wesstrom J, Nilsson S, Sundstrom-Poromaa I, Ulfberg J. Restless legs syndrome among women: prevalence, co-morbidity and possible relationship to menopause. Climacteric. 2008 Oct;11(5):422-8.

21. Molarius A, Tegelberg A, Ohrvik J. Socio-economic factors, lifestyle, and headache disorders - a population-based study in Sweden. Headache. 2008 Nov-Dec;48(10):1426-37.

22. Hasson D, Theorell T, Wallén MB, Leineweber C, Canlon B. Stress and prevalence of hearing problems in the Swedish working population. BMC Public Health. 2011 Feb 23;11:130.

23. Green LA, Fryer GE Jr, Yawn BP, Lanier D, Dovey SM. The ecology of medical care revisited. N Engl J Med. 2001 Jun 28;344(26):2021-5.

24. Fleming DM, Pavlic DR. Information from primary care: its importance and value. A comparison of information from Slovenia and England and Wales, viewed from the 'Health 21' perspective. Eur J Public Health. 2002 Dec;12(4):249-53

25. Seifert B, Svab I, Madis T, Kersnik J, Windak A, Steflova A, et al. Perspectives of family medicine in Central and Eastern Europe. Fam Pract. 2008 Apr;25(2):113-8.

26. Young JT. Illness behaviour: a selective review and synthesis. Sociol Health Illn. 2004 Jan;26(1):1-31.

27. Groves RM, Biemer PP, Lyberg LE, Massey JT, Nichols II WL, Waksberg J, editors. Telephone survey methodology. New York: John Wiley and Sons; 2001.

28. Statistical Office of the Republic of Slovenia. Slovenian national statistics [Internet]. Ljubljana: Statistical Office of the Republic of Slovenia; 2011 [cited 2011 Dec 6]. Available from: http://www.stat.si/. (In Slovenian.)

29. Eriksen HR, Ihlebaek C, Ursin H. A scoring system for subjective health complaints (SHC). Scand J Public Health. 1999 Mar;27(1):63-72.

30. Tibblin G, Tibblin B, Peciva S, Kullman S, Svärdsudd K. "The Göteborg quality of life instrument" - an assessment of well-being and symptoms among men born 1913 and 1923. Methods and validity. Scand J Prim Health Care Suppl. 1990;1:33-8.

31. Kroenke K, Spitzer RL. Gender differences in the reporting of physical and somatoform symptoms. Psychosom Med. 1998 Mar-Apr;60(2):150-5.

32. Ladwig KH, Marten-Mittag B, Formanek B, Dammann G. Gender differences of symptom reporting and medical health care utilization in the German population. Eur J Epidemiol. 2000 Jun;16(6):511-8.

33. Klemenc-Ketiš Z, Kersnik J, Novak-Glavač D. Determinants of depression and anxiety in family practice patients with comorbidities. Wien Klin Wochenschr. 2010 May;122 Suppl 2:35-9.

34. Klemenc-Ketiš Z, Kersnik J, Tratnik E. The presence of anxiety and depression in the adult population of family practice patients with chronic diseases. Zdrav Var. 2009;48:170-6.

35. Bulc M, Svab I, Pavlic DR, Kolsek M. Specialist training of Slovene family physicians. Eur J Gen Pract. 2006;12(3):128-32.

36. van Weel C. Person-centred medicine in the context of primary care: a view from the World Organization of Family Doctors (Wonca). J Eval Clin Pract. 2011 Apr;17(2):337-8. 